\title{
Análise quantitativa de células de Purkinje em camundongos sob o uso dos esteroides anabolizantes
}

\author{
Quantitative analysis of mice's Purkinje cells under the use by anabolic steroids
}

\author{
Cinthia Magalhães Ribeiro ${ }^{1}$, Dauanda Kecia Silva², Bruno Damião ${ }^{2}$, Débora \\ Mantoan Alves', Ariane Cristine de Freitas ${ }^{3}$, Wagner Costa Rossi Junior ${ }^{4}$, \\ Alessandra Esteves 5
}

\section{RESUMO}

Introduçáo. Nas últimas décadas, o uso de esteroides anabolizantes androgênicos (EAAs) tem se tornado crescente, representando um alto risco à saúde dos usuários, inclusive de ordem neurológica. Este trabalho visa elucidar mecanismos pelos quais os EAAs atuam no cerebelo, através da análise quantidade de células de Purkinje. Método. Foram utilizados 60 camundongos Swiss, divididos em seis grupos $(\mathrm{n}=10)$ : G1-Machos e Fêmeas controle, G2- Machos e Fêmeas tratados com Deposteron ${ }^{\oplus}$, G3-Machos e Fêmeas tratados com Winstrol Depot $^{\oplus}$. O tratamento durou 30 dias e consistiu na aplicação por via intraperitoneal (IP) de $0,8 \mathrm{mg} / \mathrm{Kg}$ de Deposteron ${ }^{\bullet}$ e $1,8 \mathrm{mg} / \mathrm{Kg}$ de Winstrol Depot ${ }^{\oplus}$. Os animais foram submetidos a natação, durante os 30 dias, 3 vezes por semana. A eutanásia foi realizada com inalação de Halotano ${ }^{\oplus}$ e os cerebelos armazenados no paraformaldeído $4 \%$ em tampão fosfato $\mathrm{pH} 7,4$ 0,1M. Os fragmentos foram processados e corados com violeta cresil e posterior contagem das células de Purkinje. Resultados. Pôde-se observar que não houve diferenças nos resultados entre as fêmeas. Entretanto, entre os machos do grupo Deposteron ${ }^{\circledR}$ apresentaram uma diminuição do número de células de Purkinje $(\mathrm{p}<0,05)$. Conclusáo. Conclui-se portanto que os EAA estão associados à diminuição das células de Purkinje nos animais machos tratados com Deposteron ${ }^{\oplus}$.

Unitermos. Esteroides, Anabolizantes, Cerebelo, Células de Purkinje, Camundongos

Citaçáo. Ribeiro CM, Silva DK, Damião B, Alves DM, Freitas AC, Rossi-Junior WC, Esteves A. Análise quantitativa de células de Purkinje em camundongos sob o uso dos esteroides anabolizantes.

\begin{abstract}
Introduction. In the last decades anabolic-androgenic steroids (AAS) use has increased and remains a high risk to customer's health, mainly in the neurologic aspect. This article seeks to elucidate mechanisms by which AAS act in the cerebellum, by quantitative analyzing of Purkinje cells. Method. Sixty Swiss mice were divided into 6 experimental groups $(\mathrm{n}=10)$ : $\mathrm{G} 1$ - males and female control; G2 - males and females treated with Deposteron ${ }^{\odot}$; G3 - males and females treated with Winstrol Depot ${ }^{\circ}$. The treatment lasts 30 days and consisted of intraperitoneal (IP) injection of $0.8 \mathrm{mg} / \mathrm{kg}$ of Deposteron ${ }^{\bullet}$ and $1.8 \mathrm{mg} / \mathrm{kg}$ of Winstrol Depot ${ }^{\oplus}$. The animals were also submitted to swimming thrice a week during 30 days. Euthanasia was performed by Halothane inhalation and the cerebellums were fixed in a $4 \%$ formaldehyde solution in phosphate buffer solution ( $\mathrm{pH} 7.4 \mathrm{O} .1 \mathrm{M}$ ). Fragments were processed and stained with Cresil-Violet and put to Purkinje cells counting. Results. After analyzing the samples, we could observe that there were no differences among females. However, among males treated with Deposteron ${ }^{\circledR}$ under the use of this specific AAS presented a decrease in the number of Purkinje cells $(\mathrm{p}<0.05)$. Conclusion. Therefore concluded that AAS is associated with the decrease in Purkinje cells in male animals treated with Deposteron ${ }^{\circ}$.
\end{abstract}

Keywords. Steroids, Anabolic, Cerebellum, Purkinje Cells, Mice

Citation. Ribeiro CM, Silva DK, Damião B, Alves DM, Freitas AC, Rossi-Junior WC, Esteves A. Quantitative analysis of mice's Purkinje cells under the use by anabolic steroids.
Trabalho realizado no Laboratório de Estereologia, Morfometria e Morfologia (LEMM) do Departamento de Anatomia da Universidade Federal de Alfenas, Alfenas-MG, Brasil.
1.Cirurgiă dentista graduada pela Unifal-MG, Alfenas-MG, Brasil.

2.Biomédico, Mestrando em Biociências Aplicadas à Saúde pela Unifal-MG, Alfenas-MG, Brasil.

3.Bióloga, Mestranda em Biociências Aplicadas à Saúde pela Unifal-MG, Alfenas-MG, Brasil.

4.Cirurgiấo dentista, Doutor, Docente da Unifal-MG, Alfenas-MG, Brasil.

5.Médica Veterinária, Doutora, Docente da Unifal-MG, Alfenas-MG, Brasil.
Endereço para correspondência Profa. Dra. Alessandra Esteves, Universidade Federal de Alfenas, Departamento de Anatomia. Rua Gabriel Monteiro da Silva, 700, Centro, CEP: 37130-000Alfenas-MG, Brasil.. Fone: +3532991302 E-mail:aesteves@unifal-mg.edu.br 


\section{INTRODUÇÃO}

O cerebelo é um órgão do sistema nervoso suprasegmentar, localizado sobre a fossa cerebelar do osso occipital e liga-se à medula e ao bulbo, através do pedúnculo cerebelar inferior e à ponte e mesencéfalo, através dos pedúnculos cerebelares inferior e médio. Evolutivamente, a região mais recente do cerebelo é o neocórtex cerebelar e possui três camadas de células: a camada molecular, camada de células de Purkinje e camada granular. As células de Purkinje agem como moduladoras das informaçóes aferentes que chegam ao córtex cerebelar. Tais neurônios fazem a ligação neuronal de todas as informaçóes recebidas pelo corpo e regulam a frequência, amplitude, força e direção dos movimentos musculares corporais. Ou seja, a célula de Purkinje é o elemento principal no processo de informação cerebelar e pode apresentar alteraçóes degenerativas na senescência ${ }^{1,2}$.

As principais funçóes do cerebelo estão associadas à manutenção do equilíbrio e da postura, controle do tônus muscular, controle dos movimentos voluntários e aprendizagem motora ${ }^{2}$.

O sistema nervoso central é uma das principais regióes do corpo nas quais os hormônios esteroides sexuais atuam, agindo tanto por mecanismos genômicos, modulando a síntese, liberação e metabolismo de neuropeptídeos e neurotransmissores, como por meio de mecanismos não-genômicos, influenciando a excitabilidade elétrica, a função sináptica e as características morfológicas dos neurônios ${ }^{3}$.

A testosterona é um hormônio esteroide, também conhecido como hormônio androgênio, provoca o crescimento e o desenvolvimento das gônadas masculinas na espécie humana, promovendo o desenvolvimento das características sexuais secundárias masculinas como: crescimento dos pêlos púbicos, axilares e de barba; crescimento da faringe; espessamento das cordas vocais; além de maior ativação das glândulas sebáceas e espessamento da pelé .

A testosterona também promove o efeito anabólico, que está relacionado ao crescimento de massa muscular, através da hipertrofia de fibras musculares, devido ao aumento de síntese proteica intracelular. Os anabolizantes foram criados com o intuito de potencializar esse efeito da testosterona, promovendo aumento da força de contratilidade e do volume da célula muscular, através do incremento da armazenagem de fósforo creatina (CP), balanço nitrogenado positivo, aumento da retenção de glicogênio, favorecimento da captação de aminoácidos e bloqueio do hormônio cortisol ${ }^{5}$.

Os esteroides anabolizantes ou esteroides anabólicos androgênicos (EAAs) são substâncias sintetizadas a partir do hormônio testosterona ${ }^{5}$. Assim como a testosterona, os EAAs exibem efeitos androgênicos e anabólicos. Os efeitos androgênicos são aqueles que estimulam o desenvolvimento do sistema reprodutor masculino, bem como das características sexuais secundárias e auxilia na manutenção da função reprodutora. Os efeitos anabólicos compreendem o aumento da síntese proteica nos diversos tecidos ${ }^{6}$.

O uso não médico dos EAAs foi inicialmente observado em fisiculturistas e atletas de força na década de 50. O objetivo do uso por esse perfil de indivíduo era o ganho de massa muscular e força, associado à redução de gordura corpórea ${ }^{6}$.

Nas últimas décaᄀdas, essas drogas vêm sendo utilizadas por atletas de elite, em maior parte, aqueles envolvidos em esportes de força e velocidade, para melhora do desempenho físico nas competições. Entretanto, o abuso dos esteroides anabolizantes passou a ser feito por frequenta $\neg$ dores de academias, mais interessados nas alteraçóes provocadas na composição corporal, observados com o aumento da massa magra e na redução da gordura subcutânea? .

Mesmo com a proibição do uso, os EAAs são muito utilizados por atletas profissionais e por jovens adolescentes, frequentadores de academias em todo país. Para adolescentes e jovens adultos, os esteroides representam um caminho mais curto para alcançar o porte físico magro e musculoso ${ }^{8}$.

A administração de EAA causa inúmeros efeitos adversos, como atrofia testicular e perda da libido, efeitos sobre o humor, hepatotoxicidade, tumores renais, doenças cardiovasculares, incluindo cardiomiopatia, efeitos virilizantes em mulheres e fusão das epífises ósseas. Além disso, um estudo recente demonstrou uma redução na quantidade de corpos de neurônios no córtex cerebral de camundongos sob o uso de $\mathrm{EAAs}^{10}$.

Devido à importância estrutural e funcional dos neurônios de Purkinje e o uso indiscriminado de EAAs, 
este trabalho teve como objetivo elucidar os mecanismos pelos quais os EAAs atuam no cerebelo, através análise quantitativa de células de Purkinje.

\section{MÉTODO}

\section{Amostra}

Foram utilizados neste projeto, 60 camundongos da linhagem Swiss, com idade aproximada de 90 dias (jovens-adultos), com peso corpóreo de 40 gramas, provenientes do Biotério Central da Universidade Federal de Alfenas (Unifal- MG). Os animais foram alojados em caixas individuais, tratados com ração comercial e água "ad libidum" e mantidos em ciclo de 12 horas claro-escuro. Pesquisa aprovada pelo Comitê de Ética da Universidade Federal de Alfenas (no. 479/2012).

\section{Procedimento}

Os animais foram divididos em três (3) grupos experimentais ( $\mathrm{n}=10)$, conforme Quadro 1.

O tratamento consistiu na aplicaçáo, por via intraperitoneal (IP), de dois esteroides anabolizantes, o primeiro, comercializado com o nome de Deposteron ${ }^{\oplus}$ (Cipionato de Testosterona) do Laboratório EMS sigma pharma e o segundo, comercializado pelo nome de Winstrol Depot $^{\ominus}$ (stanozolol) do Laboratório Farmaco S.A. Os animais foram tratados durante 30 dias, sendo as doses de Deposteron ${ }^{\bullet} 0,8 \mathrm{mg} / \mathrm{kg}$ e de Winstrol Depot ${ }^{\bullet}$ $1,8 \mathrm{mg} / \mathrm{kg}$ enquanto que nos animais do grupo controle utilizamos solução fisiológica na quantidade de $0,4 \mathrm{ml}^{8,9}$ aplicadas duas vezes por semana (terças e quintas-feiras). As doses, intervalos entre as aplicaçôes e o exercício físico utilizados neste experimento foram baseadas na quanti-

Quadro 1. Grupo de animais de acordo com EAA e as doses utilizada.

\begin{tabular}{|l|l|l|l|}
\hline Grupos & $\begin{array}{l}\text { Número de } \\
\text { Animais }\end{array}$ & EAA & Dosagem \\
\hline Grupo 1 & $\begin{array}{l}10 \text { machos } \\
10 \text { fêmeas }\end{array}$ & $\begin{array}{l}\text { Deposteron } \\
\text { (Cipionato de Testos- } \\
\text { terona) }\end{array}$ & $0,8 \mathrm{mg} / \mathrm{kg} / \mathrm{dia}$ \\
\hline Grupo 2 & $\begin{array}{l}10 \text { machos } \\
10 \text { fêmeas }\end{array}$ & $\begin{array}{l}\text { Winstrol Depot } \\
\text { (Stanozolol) }\end{array}$ & $1,8 \mathrm{mg} / \mathrm{kg} / \mathrm{dia}$ \\
\hline Grupo 3 & $\begin{array}{l}10 \text { machos } \\
10 \text { fêmeas }\end{array}$ & $\begin{array}{l}\text { Grupo Controle } \\
\text { (soluçáo fisiológica) }\end{array}$ & $0,4 \mathrm{ml}$ \\
\hline
\end{tabular}

dade e intervalos utilizados pelos usuários frequentadores de academias. Porém, a princípio, essa dose foi letal aos animais e, devido a isso, adequamos uma dose que é considerada alta, porém, não letal. Para isso utilizamos o método de Extrapolação Alométrica para chegarmos as doses não letais, porém supra fisiológicas.

Os animais, um dia após receberem as doses, isto é, segundas, quartas e sextas feiras, foram submetidos à natação por 15 minutos, realizada em um recipiente medindo $43 \times 34 \times 26 \mathrm{~cm}$ e contendo no seu interior água, na temperatura de $24-26^{\circ} \mathrm{C}$ até a borda, na tentativa de gerar as mesmas condições de estresse que um exercício físico, como a musculação, gera. A atividade dos animais nas sessóes de natação varia de acordo com a temperatura da água $^{10}$. A movimentação do animal na água parece estar correlacionada com as probabilidades de sobrevivência. Portanto, a diminuição da atividade do animal representaria uma resposta adaptativa. Estes autores observaram que a $25^{\circ} \mathrm{C}$ a taxa de atividade é maior do que a $39^{\circ} \mathrm{C}$. Desse modo, o nível de estresse parece ser menor a $39^{\circ} \mathrm{C}$ do que a $25^{\circ} \mathrm{C}$.

A natação forçada, além de componente físico, apresenta forte componente emocional, relacionado à novidade que este estímulo representa para o animal de laboratório e à impossibilidade de fuga somada à iminência de morte ${ }^{11,12}$.

Após o período de tratamento, os animais foram eutanasiados através de inalação do anestésico Halotano ${ }^{\oplus 13}$ prosseguindo a coleta das amostras com a abertura dos crânios e retirada dos encéfalos. O cérebro e cerebelo foram então fixados separadamente. Tais estruturas foram armazenadas em recipientes de vidro contendo paraformaldeído (Synth) a 4\% em tampão fosfato $\mathrm{pH} 7,4$ 0,1M que permaneceram imersos nesta solução fixadora por 24 horas $^{14,15}$.

Os cerebelos foram processados seguindo-se a sequência padronizada nos procedimentos histológicos convencionais: desidratação em álcool, diafanização em xilol e inclusão em parafina. Cada cerebelo foi emblocado em parafina e cortada com espessura de $7 \mu \mathrm{m}$ em micróto-

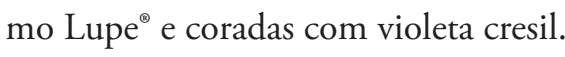

Para a estimativa da densidade por área dos perfis de corpos celulares de neurônios, no cerebelo, utilizamos a metodologia de contagem aleatória simples ${ }^{16-20}$. Neste 
de 5 cortes semi seriados da área, totalizando assim quinze áreas analisadas por animal. Nestas áreas marcamos somente os perfis dos corpos celulares de neurônios que se encontram dispostos dentro da área teste (couting frame) e na linha de inclusão (linha verde) e excluindo as células nas linhas contínuas em vermelho. Desta forma, aferimos o número de células por área contada, e não o número total dessas células no cerebelo.

\section{Análise Estatística}

$O$ estudo representa um delineamento inteiramente casualizado (DIC), portanto, a análise estatística foi realizada por meio de análise da variância (ANOVA) seguida do teste de comparação das médias de Tukey para tal análise utilizou-se o Programa GraphPad Prism 5. Valores de $\mathrm{p}<0,05$ foram considerados como indicativos de significância.

\section{RESULTADOS}

Não foram observadas diferenças nos resultados entre as fêmeas do grupo controle (7,37 corpos celulares de neurônios) com as fêmeas tratadas com osesteroides Deposteron $^{\circledast}(5,79)$ e Winstrol $^{\oplus}(5,66)$. Mostrando que as alterações nas células de Purkinje não foram relevantes (Figura 1).

Em relaçấo os machos, foi observado que entre o grupo controle (6,00 corpos celulares de neurônios) e os animais tratados com Winstrol ${ }^{\oplus}(5,84)$ não houve alterações, o mesmo fato também foi observado quando comparados animais do grupo controle $(6,00)$ com os que foram tratados com o Deposteron ${ }^{\oplus}(4,88)$. Entretando, diferenças foram observadas entre os grupos Deposteron ${ }^{\oplus}(4,88)$ e Winstrol ${ }^{\oplus}(5,84)$ quando comparados em si. Mostrando que os animais que fizeram o uso do Deposteron ${ }^{\circledast}$ apresentaram menor número de células de Purkinje quando comparado aos tratados com o Winstrol ${ }^{\oplus}(\mathrm{p}<0,05$; Figura 2$)$.

\section{DISCUSSÃo}

Os resultados encontrados no presente estudo mostram que houve diminuição quantitativa significativa entre os animais tratados com o composto Deposteron ${ }^{\ominus}$, em relação aos demais grupos. Os EAA tem sua metabolização ocorrida no fígado, entretanto para minimizar
Figura 1. Quantificação total de neurônios de purkinje nas fêmeas tratadas com Deposteron ${ }^{\oplus} \mathrm{e}$ Winstrol ${ }^{\oplus}$, mostrando que não houve uma redução de corpos celulares neuronais cerebelo de fêmeas tratadas com ambos os esteroides.

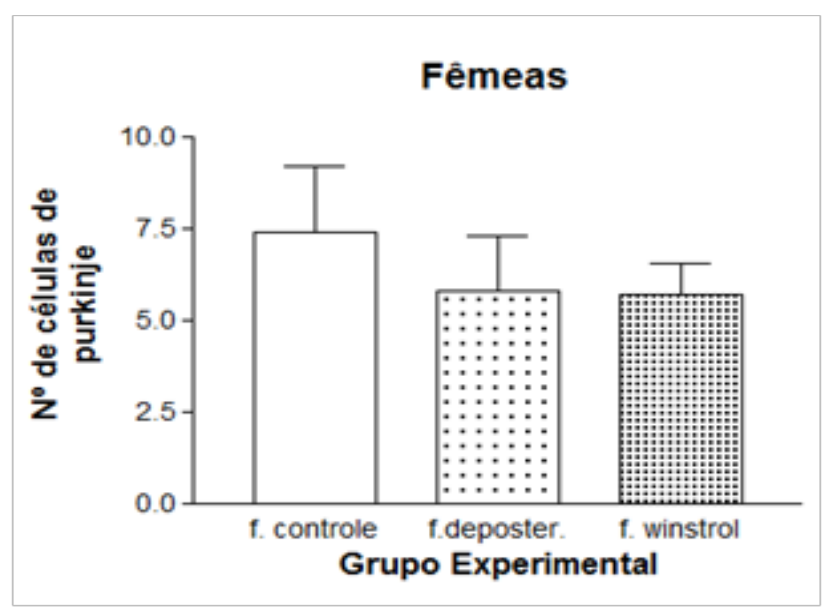

ou excluir o metabolismo hepático, a própria indústria farmacêutica estudou modificaçóes na estrutura molecular dos compostos, originando três grupos derivados: ésteres do grupo 17- $\beta$-hidroxil, do qual faz parte o cipionato de testosterona $\left(\right.$ Deposteron $\left.^{\circledR}\right)$; alquilados na posição 17- $\alpha$, representado pelo estanozol (Winstrol Depot ${ }^{\oplus}$ ); e com anel esteroide alterado ${ }^{21}$. Tal diminuição pode ser devido ao fato da esterificação do grupo $17-\beta$-hidroxil com ácidos carboxílicos diminuir a polaridade da molécula tornando-a mais solúvel nos veículos lipídicos para preparaçôes injetáveis de liberação lenta do esteroide na circulação e ocasionam menor toxicidade hepática

Figura 2. Quantificação total de neurônios de purkinje nos machos tratados com Deposteron ${ }^{\circ}$ e Winstrol ${ }^{\bullet}$, mostrando que houve uma redução de corpos celulares neuronais cerebelo de machos tratados com Deposteron ${ }^{\circledR}$ $(p<0,05)$.

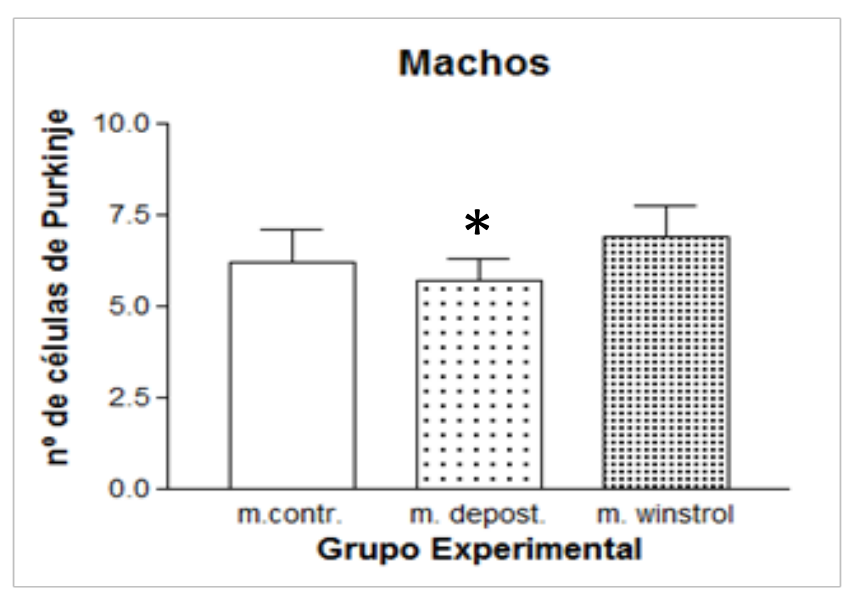


que os orais ${ }^{22}$. Este fato demonstra que o Deposteron ${ }^{\odot}$ se torne disponível por um tempo mais prolongado no organismo podendo ter maior efeitos aos sistemas. Outro ponto contribuinte para tais comprovaçóes está no fato de tal droga ser mais lipossolúvel quando comparada ao Winstrol Depot ${ }^{\oplus}$, o qual em sua versão injetável não é como o Deposteron ${ }^{\oplus}$ dissolvido em óleo e sim em água, o que nos leva a concluir que tal substância se mostra mais hidrossolúvel. Fato este que acarretaria dificuldades de atravessar a barreira hematoencefálica.

Danos às células de purkinje, ocasionando a sua diminuição foram observados, onde ratos foram submetidos exposição a solução alcoólica em água ${ }^{1}$. $\mathrm{O}$ uso de tal substância causou toxicidade devido ao fato da entrada do etanol no sistema nervoso ser livre, ou seja, não há limite para a passagem do álcool pela barreira hematoencefálica devido à sua alta lipossolubilidade. Comprovando que substâncias lipossolúveis apresentam maior facilidade de passagem, o que proporciona maior chances de danos cerebelares.

No presente estudo não foi constatado diferenças nos resultados entre fêmeas e machos. Apesar de já ser conhecido que os EAA são sintetizados a partir da testosterona, o qual apresenta concentraçóes diferentes entre homens e mulheres. A testosterona circulante nos homens varia entre 0,5 e $1,0 \mu \mathrm{g} / 100 \mathrm{~mL}$ de sangue e nas mulheres variando entre 0,03 e $0,07 \mu \mathrm{g} / 100 \mathrm{~mL}^{23}$. Devido ao fato desta maior concentração hormonal a quantidade de receptores pra tal hormônio se faz maior em machos. Em indivíduos do sexo masculino, com gônadas em funcionamento normal, os receptores androgênicos estáo saturados pelos níveis fisiológicos de testosterona. Nesse contexto doses suprafisiológicas de esteroides anabolizantes podem estimular o aumento do número de receptores androgênicos, favorecendo a expressão de suas funções.

Foi observado aumento na ordem de 106\% nos receptores após 7 dias e $279 \%$ de aumento após 21 dias de administração da droga ${ }^{24}$. Como conclusão, o autor aponta este aumento como representativo, resultado da interferência da droga. Segundo ele, o esteroide anabolizante atua sozinho, modulando o número de receptores hormonais, podendo desta forma, interferir diretamente na expressão das proteínas. Seguindo tal linha de ideias podemos conectar a presença de testosterona, endógena e exógena, a expressão de receptores celulares para estes hormônios. Somatizando a testosterona produzida normalmente ao organismo masculino à adquirida pelo uso de EAA, a quantidade ainda será maior do que a presente no organismo feminino que também está fazendo o uso de esteroides. Com isso o fato de alterações significativas presentes em machos, e ausentes em fêmeas pode ser respaldado.

Os dados encontrados neste recente experimento diferem em alguns aspectos de outro trabalho, onde camundongos foram submetidos ao uso dos anabolizantes Potenay e Deca-Durabolin ${ }^{\circledR}$ durante um mês, não demonstraram variaçóes na densidade de corpos de neurônios de purkinje no córtex cerebelar, quando comparados ao grupo controle ${ }^{15}$. Neste trabalho podemos observar uma diminuição significativa na densidade das células de Purkinje dos animais machos tratados com Deposteron ${ }^{\circ}$ quando comparados ao grupo tratado com Winstrol ${ }^{\circ}$ e também ao grupo controle, o que nos leva a sugerir que o efeito no cerebelo vai depender principalmente da dose utilizada, droga e tempo de exposição da mesma.

Apesar de não ser objetivo principal deste trabalho, o estudo comportamental destes animais, observou-se constantes brigas entre os animais machos. Ao decorrer das semanas de tratamento, a agressividade se tornou visivelmente crescente, aumentando o número de brigas e o número de animais machucados. Como pode-se observar na Figura 3, os grupos tratados com os esteroides ficaram muito mais machucados. As feridas aqui estão mais presentes na região dorsal do animal e próximo à cauda.

\section{CONCLUSÃO}

Conclui-se entáo que o número de células de Purkinje no cerebelo das fêmeas não foi diferente entre os grupos estudados; enquanto que a diminuição do número de células de Purkinje nos machos foi diferente somente para o grupo tratado com Deposteron ${ }^{\circledR}$.

\section{REFERÊNCIAS}

1.Apfel MIR, Ésberard CA, Rodrigues FKP, Bahamad-Júnior FM, Sillero RO. Estudo estereológico das células de purkinje cerebelares submetidas à intoxicação alcoólica em ratos wistar. Arq Neuropsiquiatr 2002;60:258-63. http:// dx.doi.org/10.1590/S0004-282X2002000200014

2.Machado ABM. Neuroanatomia Funcional. 2a edição. São Paulo: Atheneu, 2006, 363 p. 
Figura 3. Fotografia comparando camundongos machos dos diferentes grupos estudados. $3 A$ - Macho grupo controle sem alteraçöes significativas na pele. 3B e 3C-Macho do grupo tratado com Deposteron ${ }^{\oplus}$ e Winstrol ${ }^{\oplus}$, respectivamente, mostrando as feridas provocadas por brigas com outros animais, que estavam na mesma caixa durante o experimento.

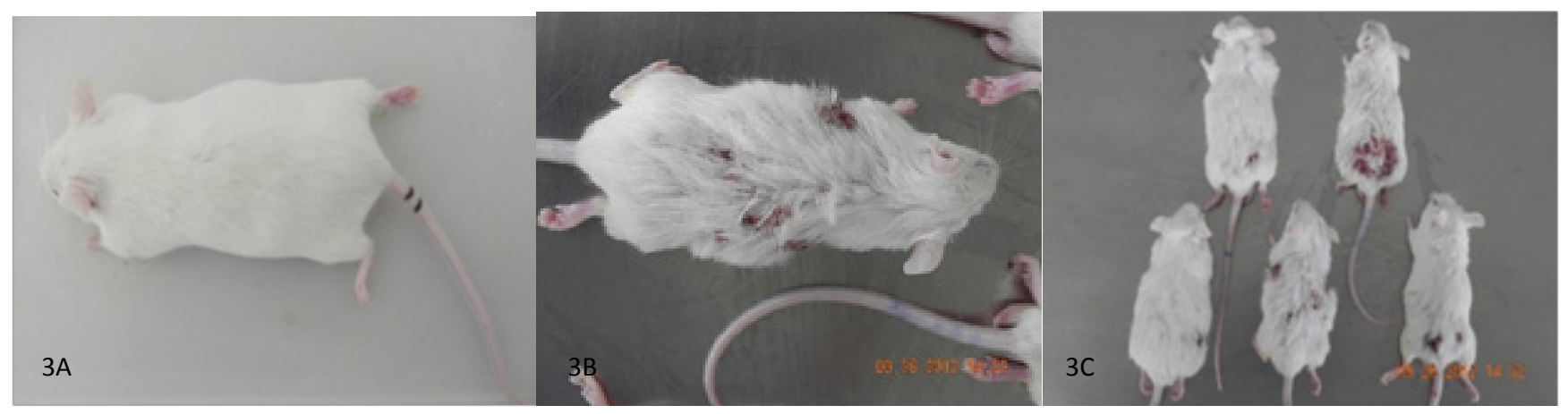

3.Silva ACJSR, Sá MFS. Efeitos dos esteroides sexuais sobre o humor e a cognição. Rev Psiquiatr Cli 2013;33:60-7. http://dx.doi.org/10.1590/S0101$\underline{60832006000200005}$

4.Cunha TS, Cunha NS, Moura MJCS, Marcondes FK. Esteroides anabólicos androgênicos e sua relação com a prática desportiva. Rev Bras Ciênc Farmaceut 2004;40:165-79. http://dx.doi.org/10.1590/S1516-93322004000200005

5.Machado NHS, Socorro M, Marinho N, Pinheiro NV, Silva PRR, Melo RF, et al. Esteróides anabolizantes: efeitos anabólicos e andrógenos. Cienc Farmaceut 2003;1:1-4.

6.Fortunato RS, Rosenthal D, Carvalho DP. Abuso de esteroides anabolizantes e seu impacto sobre a funçấo tireóidea. Arq Bras Endocrinol Metabol 2007;51:1417-24. http://dx.doi.org/10.1590/S0004-27302007000900003

7.Venâncio DP, Nóbrega ACL, Tufik S, Mello MT. Avaliação descritiva sobre o uso de esteroides anabolizantes e seu efeito sobre as variáveis bioquímicas e neuroendócrinas em indivíduos que praticam exercício resistido. Rev Bras Med Esp 2010;16:191-5. http://dx.doi.org/10.1590/S1517-86922010000300007 8. Wood RI. Anabolic-androgenic steroid dependence? Insights from animals and humans. Front Neuroendocrinol 2008;29:490-506. http://dx.doi. org/10.1016/j.yfrne.2007.12.002

9.Ritter JM. Sex, steroids and anabolic androgens in athletics. Bri J Cli Pharmacol 2012;74;1:1-2. http://dx.doi.org/10.1111/j.1365-2125.2012.04329.x 10.Bruner CA, Vargas I. The activity of rats in a swimming situation as a function of water temperature. Physiol Behav 1994;55:21-8. http://dx.doi. org/10.1016/0031-9384(94)90004-3

11.Ostman-Smith I. Adaptative changes in the sympathetic nervous system and some effector organs of the rat following long term exercise or cold acclimation and the role cardiac sympathetic nerves in the genesis of compensatory cardiac hypertrophy. Acta Phisiol Scand 1979;477:1-118.

12.Garcia-Marquez C, Armario A. Chronic stress depresses exploratory activity and behavioral performance in the forced swimming test without altering ACTH response to a novel acute stressor. Physiol Behav 1987;40:33-8. http:// dx.doi.org/10.1016/0031-9384(87)90182-X

13. Conselho Federal de Medicina Veterinaria. Rio de Janeiro: Métodos de Eu- tanásia Recomendados Pelo CFMV. (Atualizado em out/2014; acessado em ago/2014). Disponível em: www.cesed.br/portal/documentos/ceua/protocolos/MetodosEutanasia.pdf.

14.Damiáo B, Souza GG, Nogueira DA, Rossi-Junior WC, Fernandes GJM, Esteves A. Quantificação de Corpos de Neurônios em Camundongos Submetidos ao Uso de Esteroides Anabolizantes. Rev Neurocienc 2012;20:68-72.

15. Silva DK, Esteves A, Rossi Junior WC, Nogueira DA. Quantidade de células de purkinje no cerebelo de camundongos sob o uso de esteroides anabolizantes. Rev Neurocienc 2012;20:200-3. http://dx.doi.org/10.4181/ RNC.2012.20.690.4p 16. West MJ. New stereological method for counting neurons. Neurobiol Aging 1993;14:275-85. http://dx.doi.org/ 10.1016/01974580(93)90112-O

17. West MJ. Regionally specific loss of neurons in the aging human hippocampus. Neurobiol Aging 1993;14:287-93. http://dx.doi.org/10.1016/0197$\underline{-4580(93) 90113-\mathrm{P}}$

18. Mandarim-de-Lacerda CA. Manual de quantificação Morfológica: Morfometria, Alometria e Estereologia. 2.ed. Rio de Janeiro: CEBIO, 1994,131p.

19.Pakkenberg B, Gundersen HJG. Solutions to old problems in the quantitation of the central nervous system. J Neurol Sci 1995;129:65-7. http://dx.doi. org/10.1016/0022-510X(95)00067-C

20.Mandarim-de-Lacerda CA. Stereological tools in biomedical research. Anais Acad Bras Ciênc 2003;75:469-86. http://dx.doi.org/10.1590/S0001$\underline{37652003000400006}$

21.Kuhn CM. Anabolic steroids. Recent Prog Horm Res 2002;57:411-34. 22.Ferreira UMG, Ferreira ACD, Azevedo AMP, Medeiros RL, Silva CAB. Esteroides anabólicos androgênicos. RBPS 2007;20:267-75.

23.Boof SR. Esteroides anabólicos e exercício: Ação e efeitos colaterais. Rev Bras Cienc Mov 2010;18:81-8.

24.Lee WJ, Thompson RW, McClung JM, Carson JA. Regulation of androgen receptor expression at the onset of functional overload in rat plantaris muscle. Am J Physiol Regul Integr Comp Physiol 2003;285:1076-85. http://dx.doi. org/10.1152/ajpregu.00202.2003 